\title{
Association of Bovine Fatty Acid Desaturase 2 Gene Single-Nucleotide Polymorphisms with Intramuscular Fatty Acid Composition in Japanese Black Steers
}

\author{
Hideaki Takahashi1 ${ }^{*}$, Masayuki Hayashi1, Koichi Ushizawa',2, Kagetomo Nishino33, \\ Yasutoshi Haga3,4, Takao Saito3,5, Yuki Fujimori33,6, Nagako Iwama3,7, Hisato Takeda1, \\ Masanori Komatsu' ${ }^{1}$, Aduli E. O. Malau-Aduli8 \\ ${ }^{1}$ Institute of Livestock and Grassland Science, NARO, Tsukuba, Japan \\ ${ }^{2}$ Wako Safety Center, RIKEN, Wako, Japan \\ ${ }^{3}$ Beef Cattle Institute, Ibaraki Prefectural Livestock Research Center, Hitachi-Ohmiya, Japan \\ ${ }^{4}$ Ibaraki Agricultural Academy, Ibaraki, Japan \\ ${ }^{5}$ Ibaraki Prefectural Ken-Nan Livestock Hygiene Service Center, Tsuchiura, Japan \\ ${ }^{6}$ Nagano Animal Industry Experiment Station, Siojiri, Japan \\ ${ }^{7}$ Ibaraki Prefectural en-Nan Office of Agriculture and Forestry, Tsuchiura, Japan \\ ${ }^{8}$ University of Tasmania, Hobart, Australia \\ Email: *naoe@affrc.go.jp
}

Received 21 January 2016; accepted 10 April 2016; published 13 April 2016

Copyright (C) 2016 by authors and Scientific Research Publishing Inc.

This work is licensed under the Creative Commons Attribution International License (CC BY). http://creativecommons.org/licenses/by/4.0/

c) (7) Open Access

\section{Abstract}

Beef from Japanese Black cattle (JBK), is popular in Japan and valued for its highly marbled fat content. In JBK, genes affecting oleic acid content in meat have been studied mainly to lower the fat melting point and improve tenderness; however, there has been no direct correlation demonstrated between beef taste and oleic acid. To investigate genes affecting other fatty acids other than oleic acid, polymorphisms of the fatty acid desaturase 2 (FADS2) gene were genotyped and associations with fatty acid profile in JBK beef were investigated. Amplifications of 5'-flanking regions, 12 exons, and 3'-untranslated regions of the FADS2 gene in three Japanese and five Western cattle breeds via PCR, were amplified, sequenced and SNPs were identified using specific TaqMan genotyping assay. Fatty acid composition of intramuscular adipose tissue of the Trapezius muscle was analyzed in JBK steers. Six of the 15 identified SNPs are novel and have never been registered in any public bovine SNP database. A non-synonymous SNP (rs211580559; C > T; 294 Ala > Val) in exon 7 was examined in order to evaluate its association with fatty acid profiles. The data showed that highly significant association existed between rs211580559 and C18:2 (n-6) composition, and "Corresponding author.

How to cite this paper: Takahashi, H., Hayashi, M., Ushizawa, K., Nishino, K., Haga, Y., Saito, T., Fujimori, Y., Iwama, N., Takeda, H., Komatsu, M. and Malau-Aduli, A.E.O. (2016) Association of Bovine Fatty Acid Desaturase 2 Gene Single-Nucleotide Polymorphisms with Intramuscular Fatty Acid Composition in Japanese Black Steers. Journal of Biomaterials and Nanobiotechnology, 6, 105-115. http://dx.doi.org/10.4236/ojas.2016.62013 
accounted for $22.3 \%$ of the variation. There were no significant relationships between rs211580559 and the other fatty acids. It was concluded that rs211580559 of the FADS2 gene may be a useful selection marker for reducing unfavorable volatiles generated from linoleic acid in JBK beef during the cooking process.

\title{
Keywords
}

\author{
Japanese Black Cattle, Beef, Fatty Acid Desaturase 2, Single-Nucleotide Polymorphism, Fatty Acid \\ Composition
}

\section{Introduction}

Japanese Black (JBK) cattle were developed during the Meiji era (1868-1912) by crossbreeding Japanese native and Western cattle, e.g. Simmental and Swiss Brown breeds. Japanese beef farmers have focused on the improvement of marbling in JBK cattle, and fat quality itself has become an important factor in determining beef palatability. Characteristics and historical background of JBK cattle were introduced in Namikawa (2008) [1].

In JBK cattle, genes affecting oleic acid composition (C18:1 (n-9)), i.e., fatty acid synthase (FASN) [2], stearoyl-CoA desaturase (SCD) [3], and sterol regulatory element binding protein-1 (SREBP1) [4], have been reported. C18:1 (n-9) is one of the major monounsaturated fatty acids in beef fat and has been thought to be related to the aroma and melting properties of tallow [5], although no direct correlation has been demonstrated between beef taste and C18:1 (n-9). Kiyohara et al. (2011) [6] and Takahashi et al. (2012) [7] reported direct evidence for significant positive associations among arachidonic acid (C20:4 (n-6)) and flavor intensity, total taste intensity, umami (L-glutamate taste) and aftertaste in chicken meat. Meanwhile, studies that have measured the C20:4 (n-6) content in beef are limited because of its extremely low levels.

$\mathrm{C} 20: 4(\mathrm{n}-6)$ originates from both dietary sources, elongation and desaturation processes of its precursor, linoleic acid (C18:2 (n-6)). The $\delta-5$ (D5D) and $\delta-6$ (D6D) desaturases are key enzymes involved in this pathway [8] (Figure 1). D6D catalyzes the conversion of C18:2 (n-6) to $\gamma$-linolenic acid (C18:3 (n-6)), which is then elongated to dihomo- $\gamma$-linolenic acid (C20:3 (n-6)) by elongases, mainly elongase 5 (EL5) [9]. In turn, C20:3 (n-6) is desaturated to C20:4 (n-6) by D5D. EL5, D5D and D6D are also involved in the n-3 fatty acid pathway (Figure 1), which favors the conversion of $\alpha$-linolenic acid (C18:3 (n-3)) into docosahexaenoic acid (C22:6 (n-3)). D5D and D6D are encoded by fatty acid desaturase 1 and 2 genes (FADS1 and FADS2), respectively. Therefore, we hypothesize that EL5, FADS1, and FADS2 are the key gene variants that control both $\mathrm{C} 20: 4$ (n-6) and $\mathrm{C} 22: 6(\mathrm{n}-3)$ in beef.

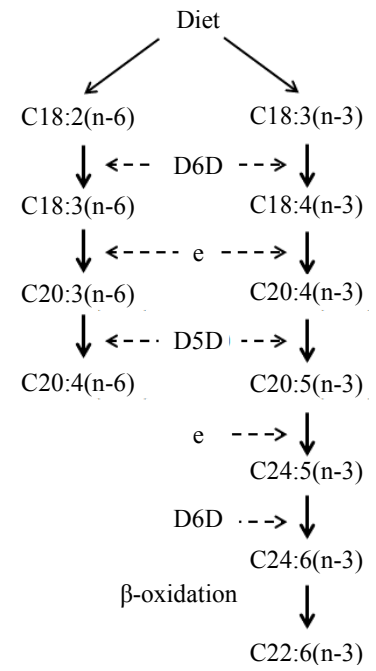

Figure 1. Synthetic pathway of long chain unsaturated fatty acids. D6D: $\delta-6$ desaturase; D5D: delta-5-desaturase; e: elongases. 
Of the three candidate genes, we herein focus our investigation on the FADS2 because D6D catalyzes the first steps in the biosynthesis of C20:4 (n-6) and C22:6 (n-3). Therefore, the main objective in this study was to analyze polymorphisms of the FADS2 gene and test for associations with intramuscular fatty acid profile in JBK steers.

\section{Materials and Methods}

\subsection{Sample Collection and Identification of FADS2 Polymorphisms}

Genomic DNA was collected from the following cattle breeds and locations: JBK cattle from Ibaraki Prefectural Livestock Research Center (Hitachi-Ohmiya, Ibaraki, Japan), Japanese Brown (JBN) cattle from Kochi Prefecture, Japanese Shorthorn (JS) cattle from Iwate Prefectural Livestock Research Center (Takizawa, Iwate, Japan), Mishima Island (MI) cattle from Mishima Island (Yamaguchi Prefecture), Angus and Hereford cattle from Tokachi Station of the National Livestock Breeding Center (Otohuke, Hokkaido, Japan), Holstein cattle from the Livestock Improvement Association (Tokyo, Japan), Jersey cattle from Okayama Prefectural livestock Research Center (Misaki, Okayama, Japan), and Swiss Brown cattle from Hinobori Farm (Un-nan, Shimane, Japan). The three Japanese breeds (9 JBK, $6 \mathrm{JBN}$ and $5 \mathrm{MI}$ cattle) and five Western breeds (5 Angus, 6 Hereford, 4 Holstein, 6 Jersey, and 6 Swiss Brown) were tested for sequence comparison in order to identify DNA polymorphisms. For each sample, genomic DNA was extracted from hair shafts and leukocytes using proteinase K digestion, followed by phenol-chloroform extraction and ethanol precipitation [10].

A draft sequence of the bovine genome (October 2011 assembly), available on the University of California, Santa Cruz (UCSC) Genome Browser [11] and the Ensembl Genome Browser [12], was used in this study. The nucleotide sequences of the 5'-flanking regions, 12 exons and the 3'-untranslated regions (3'-UTR) of FADS2 in the cattle samples were determined using polymerase chain reaction (PCR), followed by direct sequencing to determine nucleotide variance of the gene. Fifteen PCR primer pairs (Table 1) were designed using Primer 3 in DNASIS Pro software (ver. 3, Hitachi Software Engineering, Kanagawa, Japan).

For PCR, we used $20-\mu \mathrm{L}$ reaction volumes containing the following: 6.0 pmol of each primer for each pair, $0.2 \mu \mathrm{M}$ of each deoxyribonucleotide triphosphate (dNTP), $1.5 \mathrm{mM}$ magnesium sulfate $\left(\mathrm{MgSO}_{4}\right), 0.4$ units of KOD plus ver. 2 polymerase (TOYOBO, Osaka, Japan), $1 \times$ reaction buffer provided by the manufacturer (TOYOBO), and 10 ng genomic DNA. Reactions were performed in a 96-well plate in a Gene Amp PCR system

Table 1. Primers for bovine fatty acid desaturase 2 (FADS2) sequencing.

\begin{tabular}{|c|c|c|c|c|c|}
\hline Set & Primer name ${ }^{1}$ & Forward $\left(5^{\prime} \rightarrow 3^{\prime}\right)$ & $\operatorname{Reverse}\left(5^{\prime} \rightarrow 3^{\prime}\right)$ & Product (bp) & $\begin{array}{l}\text { Annealing } \\
\text { temp. }\left({ }^{\circ} \mathrm{C}\right)\end{array}$ \\
\hline 1 & 5'-flanking region 1 & GGCCAGAACCAAGTCCTC & GGTACGTGTCCGAACTCCTC & 544 & 64 \\
\hline 2 & 5'-flanking region 2 & TCTTTGTGCGGGCATCAG & CCTGCAAAACTCCTGGGTAG & 428 & 64 \\
\hline 3 & 5'-flanking region 3 & GGCAGAGGAGGTTTCGAG & GTAGACCTTGCGATCGATGA & 420 & 58 \\
\hline 4 & Exon 1 & GAAGACAAAAGCCGAAAGGA & CGCTGGAGGTCTTGTCTGA & 375 & 58 \\
\hline 5 & Exon 2 & AGCCGCAGTAGAGGTCTTTG & TTCCTCATCCGGTCAGACTC & 181 & 58 \\
\hline 6 & Exon 3 and 4 & TGACTCCTTCCTCGTGCTCT & GTGCCCACCCACTAACTGAT & 500 & 58 \\
\hline 7 & Exon 5 & CCTGCTCATCCCTGTTCCT & CCCATCCCCTTCATCGTA & 175 & 60 \\
\hline 8 & Exon 6 and 7 & GGGCTCACAGTCTCTGCTTC & ССТССТССССАСАСТССТ & 579 & 62 \\
\hline 9 & Exon 8 and 9 & GCAAGACACTCCCACGTCTA & TCCTGGGGACATGGACCT & 553 & 58 \\
\hline 10 & Exon 10 & CTTTGTGCTTCTGCTTCCAG & TCCACTGTATGCCCTCCAC & 178 & 64 \\
\hline 11 & Exon 11 & AGAGGCGGACAGGGTCTC & ATGCCCACCCCTCCTTAC & 238 & 62 \\
\hline 12 & $\begin{array}{l}\text { Exon } 12 \text { and } \\
3 \text { '-untranslated region } 1\end{array}$ & САТССАТТТССТССТСТТСС & GGCCCTGGACATCTGAAG & 599 & 58 \\
\hline 13 & 3'-untranslated region 2 & TTCTGTGGGGTGATGATGTG & TTGATAGACCGGGAAAGAGC & 555 & 62 \\
\hline 14 & 3'-untranslated region 3 & AGCCCAGCAGCTCATCAC & TTCTCAGTGGGAGGGCTTC & 573 & 62 \\
\hline 15 & 3'-untranslated region 4 & CAGCTCTGACTGGTGATGGA & $\begin{array}{l}\text { AACGGGAAGTGGAGGAGAA } \\
\mathrm{T}\end{array}$ & 244 & 58 \\
\hline
\end{tabular}

\footnotetext{
${ }^{1}$ Primer name indicates the region of the gene amplified by polymerase chain reaction (PCR).
} 
9700 (Thermo Fisher Scientific, Waltham, MA, USA) using the following conditions: initial denaturation for 2 min at $94^{\circ} \mathrm{C} ; 40$ cycles of the following: $10 \mathrm{~s}$ at $98^{\circ} \mathrm{C}, 30 \mathrm{~s}$ at $x^{\circ} \mathrm{C}$ ( $x$ was the annealing temperature shown in Table 1), $1 \mathrm{~min}$ at $68^{\circ} \mathrm{C}$; and final elongation for $10 \mathrm{~min}$ at $68^{\circ} \mathrm{C}$. The amplified PCR products were then purified using ExoSAP-IT (Affymetrix, Santa Clara, CA, USA).Following purification, the PCR products were sequenced using forward and reverse primers of each regions and the BigDye terminator v3.1 cycle sequencing kit (Thermo Fisher Scientific) on an ABI PRISM 3730 DNA analyzer (Thermo Fisher Scientific). Micro RNA binding prediction sites on DNA sequence data were searched using TargetScan Release 6.2 software [13]. Linkage disequilibrium (LD) block analysis and haplotype estimation were performed by Haploview software [14].

\subsection{SNP Genotyping}

A specific TaqMan genotyping assay was developed for a target SNP using Type-it Fast SNP Probe PCR kit (Qiagen, Venlo, Netherlands). Primers and probes for the assay were designed using DNASIS Pro software (Hitachi Software Engineering). Pre-and post-PCR fluorescent measurements and PCR were performed. The PCR was conducted in a total volume of $20 \mu \mathrm{L}$, containing 22.5 pmol of each primer and 5 pmol each probe, $1 \times$ Type-it Fast SNP Probe PCR master mix, and 20 ng of genomic DNA. Reactions were performed in a 96-well plate in an ABI PRISM 7500 (Thermo Fisher Scientific) using the following conditions: initial denaturation for $2 \mathrm{~min}$ at $95^{\circ} \mathrm{C} ; 40$ cycles of the following: $15 \mathrm{~s}$ at $95^{\circ} \mathrm{C}, 31 \mathrm{~s}$ at $60^{\circ} \mathrm{C}$. SNP call of each sample was determined by Taqman Genotyper software (ver. 1.3, Thermo Fisher Scientific). SNP and haplotype frequencies among breeds were analyzed by Fisher's exact test with the Bonferroni correction.

\subsection{Determination of Fatty Acid Composition}

Intramuscular adipose tissue was sampled from the seventh and eighth ribs interface of the Trapezius muscle at the Ibaraki Central Meat Center (Ibaraki Town, Ibaraki, Japan) from 2007 to 2009. The average age of 133 steers of JBK cattle was 30.7 months. To determine the fatty acid composition, lipids were extracted using a chloroform:methanol (2:1, vol/vol) solution according to the method of Folch et al. (1957) [15]. Dried hydrophobic fractions were added to $10 \mathrm{~mL}$ toluene (HPLC grade, Wako Pure Chemical Industries, Ltd., Osaka, Japan) and $1 \mathrm{~mL}$ of them were methyl-esterified by $2 \mathrm{~mL}$ of methanolic base (Sigma-Aldrich, St. Louis, Missouri) for $15 \mathrm{~min}$ at $78^{\circ} \mathrm{C}$. The fatty acid methyl esters were quantified by GC-400 gas chromatography (GL science, Tokyo, Japan) with a DB-23 122-2361 column (Agilent Technologies, Santa Clara, California), and chromatograms were recorded using a computing integrator. The fatty acids were identified by comparing the relative retention times of the fatty acid methyl esters with those of standards, and the relative proportions of these esters were determined in terms of percentages of the total peak areas.

\subsection{Statistical Analysis}

A mixed-inheritance animal model was used to evaluate the effect of genotype and compute basic summary statistics on traits of interest. The snp_ad, snp_a, and snp_d options of Qxpak software [16] was used for analyzing the additive and dominant effects of individual SNP. The following models were used:

$$
y=\text { year }_{i}+\text { month }_{j}+b x_{k}+\mathrm{SNP}+u_{i j k}+e_{i j k}
$$

where $y$ is an individual phenotypic observation; the effects of year ${ }_{i}(3$ levels, 2007 to 2009) and slaughter month (month $j, 12$ levels) were used as fixed effects. $b$ is a regression coefficient of slaughter age (months) $\left(x_{k}, 8\right.$ levels). In this analysis, the infinitesimal genetic effect was included and treated as a random effect $\left(u_{i j k}\right)$ with covariance matrix, $A \sigma_{u}^{2}$ (where $\mathrm{A}$ is the numerator relationship matrix), and $e_{i j k}$ is a vector of random residual effect. SNP is the single-locus SNP genotypic effect, which was partitioned into additive $(a)$ and dominance $(d)$ effects. Pedigrees of the base population animals were traced as far back as possible based on pedigree records collected by the Japan Wagyu Registry Association (Kyoto, Japan) to create the numerator relationship matrix, and 1243 animals were included in the pedigree analysis.

The likelihood ratio test was performed by removing the single locus SNP genotypic effect from the model, and normal P-values were obtained by assuming a $x^{2}$ distribution of the likelihood ratio test.

The proportion of additive genetic variance explained by the model was calculated as follows:

$$
\text { variance percentage }=\left[2 p q(a+d(q-p))^{2}\right] / V_{A}
$$


where $p$ and $q$ were allelic frequencies at the SNP locus, and $V_{A}$ was the additive genetic variance of the trait obtained from an animal model analysis ignoring the single SNP genotypic effects [17].

\section{Results}

As shown in Table 2, a total of 15 SNPs was found in 5'-flanking regions, 12 exons, and 3'-UTR. The nucleotide sequences containing the SNPs were registered in the DNA Data Bank of Japan (DDBJ). The accession numbers of the sequences are shown in Table 3. Of the 15 SNPs, six have never been previously documented in any cattle breed. Of the $15 \mathrm{SNPs}$, three were located in 5'-flanking regions, three in exons 2, 7, and 11, and nine

Table 2. Primers and probes used in the TaqMan assay for SNP genotyping.

\begin{tabular}{|c|c|c|c|c|}
\hline Location & SNP, rs No. ${ }^{1}$ & Forward primer/Reporter 1 sequence & primer/Reporter & $\begin{array}{l}\text { Product } \\
\text { (bp) }\end{array}$ \\
\hline Exon 2 & $\begin{array}{l}\mathrm{C}>\mathrm{A}, \\
\text { rs } 135659079\end{array}$ & $\begin{array}{l}\text { CGCAGTAGAGGTCTTTGTATTCAC/ } \\
\text { FAM-CCTTCCACCGCAACCTTGATTT-MGB }\end{array}$ & $\begin{array}{l}\text { CCAGCTCGCCAATTAACAG/ } \\
\text { VIC-CCTTCCACCGCAACATTGATTT-MGB }\end{array}$ & 121 \\
\hline Exon 7 & $\begin{array}{l}\mathrm{C}>\mathrm{T} \\
\mathrm{rs} 211580559\end{array}$ & $\begin{array}{l}\text { AGGGTCTAGTCGCCCTCCT/ } \\
\text { FAM-CACCGCCCAGTACTTGCGA-MGB }\end{array}$ & $\begin{array}{l}\text { CTGCTCATCCCTTTGTATTTCC/ } \\
\text { VIC-ACCACCCAGTACTTGCGAACGA-MGB }\end{array}$ & 114 \\
\hline
\end{tabular}

${ }^{1}$ Reference SNP ID number.

Table 3. SNPs in bovine fatty acid desaturase 2 (FADS2).

\begin{tabular}{|c|c|c|c|c|}
\hline Position $^{1}$ & Location and characteristics & SNP allele & Accession No. $^{2}$ & rs No. ${ }^{3}$ \\
\hline \multirow[t]{2}{*}{-879} & 5'-flanking region & $\mathrm{C}$ & AB669287 & NR \\
\hline & & $\mathrm{T}$ & AB669293 & \\
\hline \multirow[t]{2}{*}{-823} & 5'-flanking region & G & AB669287 & rs382438496 \\
\hline & & A & AB669299 & \\
\hline \multirow[t]{2}{*}{-592} & 5'-flanking region & G & AB669287 & NR \\
\hline & & $\mathrm{T}$ & AB669301 & \\
\hline \multirow[t]{2}{*}{12058} & Exon 2, non-synonymous substitution (79 Leu > Ile) & $\mathrm{C}$ & AB669305 & rs 135659079 \\
\hline & & A & AB669312 & \\
\hline \multirow[t]{2}{*}{28276} & Exon 7, non-synonymous substitution $(294$ Ala $>$ Val $)$ & $\mathrm{C}$ & AB669315 & rs211580559 \\
\hline & & $\mathrm{T}$ & AB669323 & \\
\hline \multirow[t]{2}{*}{35018} & Exon 11 , synonymous substitution (418 Pro) & G & AB669336 & rs 110439447 \\
\hline & & A & AB669337 & \\
\hline \multirow[t]{2}{*}{35447} & 3'-untranslated region & $\mathrm{C}$ & AB669341 & NR \\
\hline & & $\mathrm{T}$ & AB669350 & \\
\hline \multirow[t]{2}{*}{35589} & 3'-untranslated region & G & AB669357 & rs42186973 \\
\hline & & A & AB669361 & \\
\hline \multirow[t]{2}{*}{35632} & 3'-untranslated region, micro RNA binding site (bta-miR-744) & $\mathrm{G}$ & AB669357 & rs 210169303 \\
\hline & & A & AB669366 & \\
\hline \multirow[t]{2}{*}{35696} & 3'-untranslated region, micro RNA binding site (bta-miR-2381) & $\mathrm{C}$ & AB669357 & NR \\
\hline & & $\mathrm{G}$ & AB669368 & \\
\hline \multirow[t]{2}{*}{35748} & 3'-untranslated region & $\mathrm{C}$ & AB669374 & NR \\
\hline & & A & AB669384 & \\
\hline \multirow[t]{2}{*}{35826} & 3'-untranslated region & G & AB669374 & rs110020495 \\
\hline & & $\mathrm{A}$ & AB669379 & \\
\hline \multirow{2}{*}{36367} & 3'-untranslated region & $\mathrm{C}$ & AB669390 & rs 42186972 \\
\hline & & $\mathrm{T}$ & AB669392 & \\
\hline \multirow{2}{*}{36938} & 3'-untranslated region & G & AB669403 & NR \\
\hline & & $\mathrm{T}$ & AB669412 & \\
\hline \multirow[t]{2}{*}{36971} & 3'-untranslated region & G & AB669403 & rs 208312639 \\
\hline & & A & AB669411 & \\
\hline
\end{tabular}

$\mathrm{NR}=$ not reported; ${ }^{1}$ First base of exon 1 was defined as position $+1 ;{ }^{2} \mathrm{DDBJ}$ accession number of each sequence that contains each SNP; ${ }^{3}$ Reference SNP ID number. 
within the 3'-UTR. Of the 3 SNPs in the exon regions, two were in exons 2 and 7 and non-synonymous (79 Leu $>$ Ileand 294 Ala $>$ Val, respectively), while one SNP in exon 11 was synonymous (418 Pro). Two SNPs at positions 35632 and 35696, within the 3'-UTR, were predicted to be microRNA binding sites of bta-miR-744 and bta-miR-2381, respectively. As shown in Figure 2, no LD blocks were detected in the sequenced region.

Since SNPs in exons 2 and 7 (rs135659079 and rs211580559) were non-synonymous, we hypothesize herein that the two SNPs might be associated with fatty acid composition in beef. Sequences of the primers and the probes for the TaqMan genotyping assay used to detect the two SNPs are shown in Table 2. Frequencies of each allele and haplotype constructed by the two SNPs were analyzed in three Japanese cattle breeds (133 JBK, 28 MI, and $23 \mathrm{JS}$ ), and 31 Holstein cattle. Allele and haplotype frequencies in the four breeds are shown in Table 4 and Table 5. The predominant SNP allele at rs135659079 in JBK, JS and Holstein cattle was C, whereas in MI cattle, it was A. The predominant SNP allele at rs211580559 in JBK, MI and JS cattle was C, whereas in Holstein cattle, it was A. As a result, the predominant haplotype constructed by rs135659079 and rs211580559 in JBK and JS cattle was C-C, whereas in MI cattle, the predominant haplotype was A-C. In Holstein cattle, C-C and $\mathrm{C}-\mathrm{T}$ were evenly distributed. Haplotype frequencies were significantly different $(\mathrm{P}<0.01)$ among the tested breeds. JBK cattle displayed a different haplotype frequency from that of MI and Holstein cattle, while MI cattle showed a different haplotype frequency from all other breeds.

The association between rs211580559 and fatty acid composition was tested. These were the same samples used for SNP typing, since the SNP in exon 2 (rs135659079) was less polymorphic than in exon 7 (rs211580559) in the JBK cattle. The number of individuals inheriting the CC, CT and TT genotypes at rs211580559 was 109, 23 and 1, respectively. The distribution of rs211580559 genotypes in the steers was in close agreement with Hardy-Weinberg equilibrium proportions, since frequencies of $\mathrm{C}$ and $\mathrm{T}$ alleles were 0.906 and 0.094 , respectively.C18:2 (n-6) composition was significantly higher in the CC group $(2.40 \% \pm 0.53 \%)$ than in the CT group $(2.05 \% \pm 0.40 \%)$ by Student's t test $(\mathrm{P}<0.01$, effective size: $\mathrm{d}=0.75$, statistical power: $1-\beta=$ 0.90). As shown in Table 6, a highly significant association between rs211580559 and C18:2 (n-6) composition

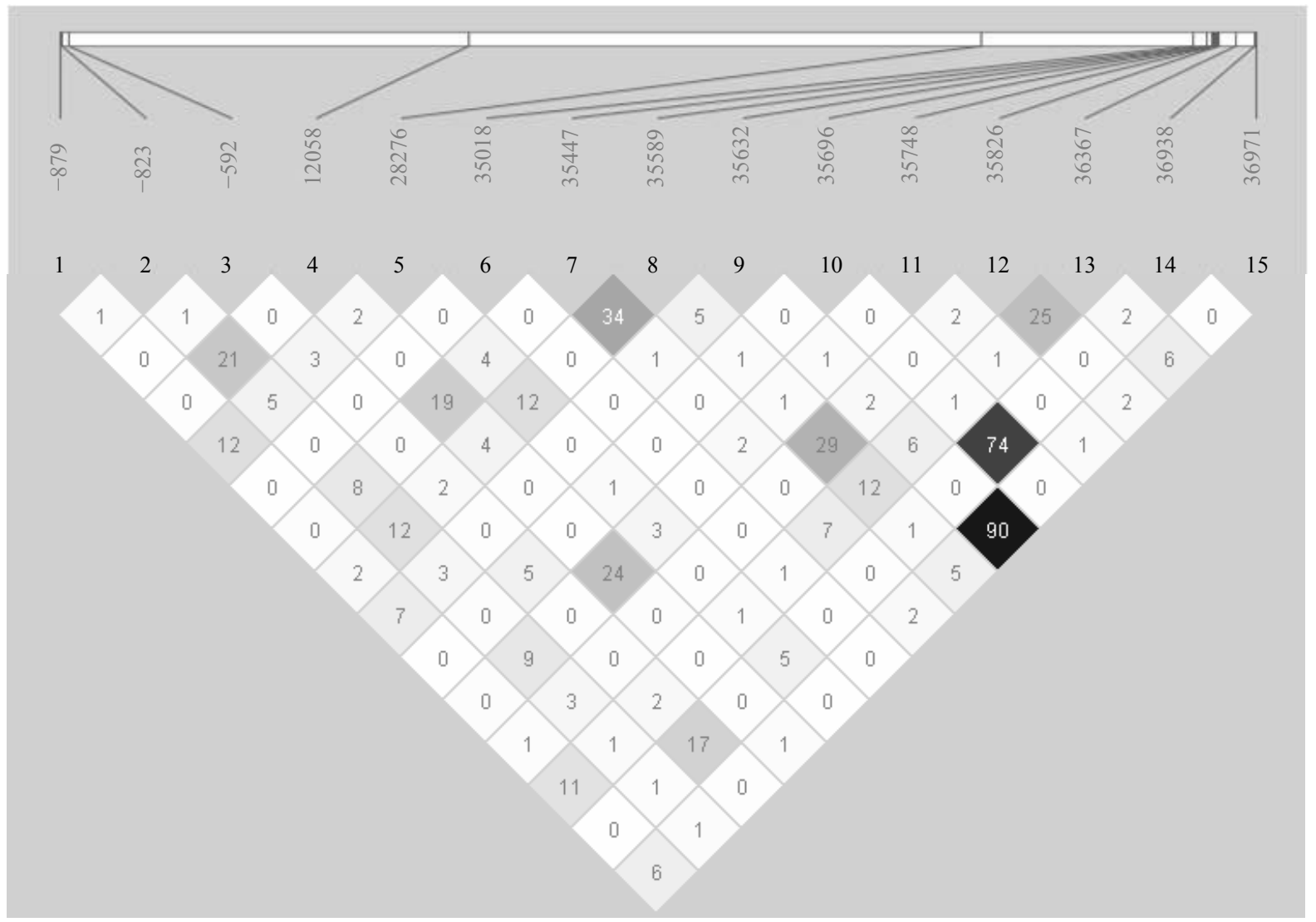

Figure 2. Linkage disequilibrium (LD) plot of fatty acid desaturase 2 (FADS2) SNPs. Numbers at center of each square are the correlation coefficients $\left(\mathrm{R}^{2}\right)$ between 2 SNPs. 
Table 4. Allele frequencies of rs135659079 and rs211580559 in Japanese cattle breeds.

\begin{tabular}{|c|c|c|c|c|c|}
\hline \multirow[b]{2}{*}{ Breed } & \multirow[b]{2}{*}{$n$ of individuals } & \multicolumn{2}{|c|}{ Exon2, rs135659079 } & \multicolumn{2}{|c|}{ Exon 7, rs211580559 } \\
\hline & & $\mathbf{A}$ & $\mathbf{C}$ & C & $\mathbf{T}$ \\
\hline Japanese Black & 133 & 0.019 & 0.981 & 0.906 & 0.094 \\
\hline Mishima Island cattle & 28 & 0.804 & 0.196 & 1.000 & 0.000 \\
\hline Japanese Shorthorn & 23 & 0.000 & 1.000 & 0.870 & 0.130 \\
\hline Holstein & 31 & 0.000 & 1.000 & 0.452 & 0.548 \\
\hline
\end{tabular}

Table 5. Haplotype frequencies of rs135659079 and rs211580559 in Japanese cattle breeds.

\begin{tabular}{|c|c|c|c|c|c|}
\hline Breed & $n$ of individuals & $2 \mathrm{C} 7 \mathrm{C}$ & $2 \mathrm{C} 7 \mathrm{~T}$ & $2 \mathrm{~A} 7 \mathrm{C}$ & \\
\hline Japanese Black & 133 & 0.887 & 0.094 & 0.019 & a \\
\hline Mishima Island cattle & 28 & 0.196 & 0.000 & 0.804 & $\mathrm{~b}$ \\
\hline Japanese Shorthorn & 23 & 0.870 & 0.130 & 0 & a \\
\hline Holstein & 31 & 0.452 & 0.548 & 0 & $\mathrm{c}$ \\
\hline
\end{tabular}

2C7C, $\mathrm{C}$ and $\mathrm{C}$ allele combination at rs135659079 in exon 2 and rs211580559 in exon 7; 2C7T, C and T allele combination at rs135659079 and rs211580559; 2A7C, A and C allele combination at rs135659079 and rs211580559. ${ }^{\mathrm{a}, \mathrm{b}, \mathrm{c}}$ Different letters indicate significant difference in haplotype frequencies among breeds $(\mathrm{P}<0.01)$.

Table 6. Effect of rs 211580559 SNP on muscle fatty acid composition (\%) in Japanese Black steers.

\begin{tabular}{|c|c|c|c|c|c|c|c|c|c|}
\hline Trait (\%) & Abbreviation & Mean & SD & Additive effect [a] & & Dominant effect [d] & & $\mathrm{V}_{\mathrm{A}}$ & Variance $(\%)$ \\
\hline Myristic acid & $\mathrm{C} 14: 0$ & 2.76 & 0.46 & -0.13 & ns & 0.111 & ns & - & - \\
\hline Myristoleic acid & $\mathrm{C} 14: 1$ & 1.88 & 0.44 & -0.163 & ns & 0.154 & ns & - & - \\
\hline Palmitic acid & $\mathrm{C} 16: 0$ & 26.25 & 1.92 & -0.482 & $\mathrm{~ns}$ & 0.388 & ns & - & - \\
\hline Palmitoleic acid & $\mathrm{C} 16: 1$ & 6.98 & 1.19 & -0.212 & ns & 0.351 & ns & - & - \\
\hline Stearic acid & $\mathrm{C} 18: 0$ & 6.44 & 1.05 & 0.243 & ns & -0.29 & ns & - & - \\
\hline Oleic acid & C18:1 & 53.36 & 2.67 & 0.786 & ns & -0.694 & ns & - & - \\
\hline Linoleic acid & $\mathrm{C} 18: 2$ & 2.33 & 0.52 & 0.391 & $* * *$ & -0.375 & ** & 0.110 & 22.3 \\
\hline
\end{tabular}

${ }^{\mathrm{ns}}$ : not significant; ${ }^{* *}$ : statistically significant at $\mathrm{P}=0.01$ level; ${ }^{* * *}$ : statistically significant at $\mathrm{P}=0.001$ level; $\mathrm{V}_{\mathrm{A}}$ : additive genetic variance.

was observed. The SNP effect on genetic variance in C18:2 (n-6) composition accounted for $22.3 \%$ of the observed variance. There were no significant differences between rs211580559 and the other fatty acid compositions.

\section{Discussion}

Flavor results from the combined effects of the five basic tastes (sweet, sour, bitter, salty and umami) and is derived from water-soluble compounds in food products. Odor is derived from volatile substances present in the food products, either inherent to the product from the outset, or derived via various reactions [18]. The main reactions that occur during the cooking of meat (resulting in the production of volatiles) are the Maillard reactions between amino acids and reducing sugars, and the thermal degradation of lipids [19]. Extensive research has suggested that the basic meaty aroma is derived from the water-soluble fraction of the muscle, whereas the species-specific differences in aroma of cooked meats are due to the concentration and compositional differences in lipid-derived flavor substances [20] [21].

Lipid oxidation is a major cause of deterioration in meat quality [22]. The oxidation of lipids during storage is known to produce off-flavors and rancidity [23]. Since the main polyunsaturated fatty acids comprising the lipids of beef are C18:2 (n-6) andC18:3 (n-3), beef off-flavors are mainly derived from these two fatty acids. The susceptibility of unsaturated fatty acids to autoxidation varies according to the lability of their allylic hydrogens. Autoxidation of linoleate at $40^{\circ} \mathrm{C}$ primarily produces pentane, 2, 4-decadienal, 2-heptenal and hexanal, whereas autoxidation of linolenate at $40^{\circ} \mathrm{C}$ primarily produces propanal, 2, 4, 7-decatrienal and 2, 4-heptadienal [24]. Of 
the volatiles, it is likely that pentane and propanal are the major causative compounds of off-flavors, because they have low boiling temperatures $\left(36^{\circ} \mathrm{C}\right.$ and $48^{\circ} \mathrm{C}$, respectively).

$\mathrm{C} 18: 1$ (n-9) and C18:2 (n-6) are found in higher concentrations in grain-based than grass-based diets, whereas C18:3 (n-3) is higher in grass-based diets [25]. Therefore, the biggest difference in the flavor of meat from grass-and grain-fed cattle is suggested to be due to fatty acid profiles in beef. In cooked beef, compounds which are derived from C18:2 (n-6) (hexanal and 2, 4-decadienal) are usually found in higher concentrations in meat from grain-fed animals, whereas 2, 4-heptadienal (products of C18:3 (n-3)) is typically found in higher concentrations in meat from grass-fed animals [26]. Although C18:1 (n-9) is more stable than C18:2 (n-6) and C18:3 (n-3), oxidized compounds from C18:1 (n-9) may affect cooked beef odors. Volatiles from heated triolein dominate heptanal, octanal, nonanal, decanal, $(E)$-2-decenal, and (E)-2-undecenal [27].

Representative dishes of JBK beef are "Shabu-shabu" and "Sukiyaki" [28] and have the taste of briefly boiled beef. Litwinienko and Kasprzycka-Guttman (2000) [29] reported that the ratio of oxidation rate constants of mono-, di-and tri-unsaturated esters at $90^{\circ} \mathrm{C}$ is $1: 3: 12$. We hypothesize that volatiles generated from $\mathrm{C} 18: 1$ (n-9) contain key substances for identifying JBK beef based on differences in odor, since the content of C18:1 (n-9) is much higher than that of C18:2 (n-6) and C18:3 (n-3) in the fatty acid composition of JBK beef. Boylston et al. (1996) [30] reported that in roasted and boiled beef, volatile lipid oxidation products were higher in Japanese and American JBK beef than in Angus, Longhorn, and US Choice beef. The authors suggested that the results simply reflect the neutral lipid contentsof the four beef, since the contents of JBK beef (23.5 - $23.9 \mathrm{~g}$ of lipid/100 $\mathrm{g}$ of cooked weight) were significantly higher than those of the three beef sources $(9.5-15.4 \mathrm{~g}$ of lipid/100 $\mathrm{g}$ of cooked weight) [31].

Matsuishi et al. (2004) [32] collected volatile components from JBK and Australian beef using a simultaneous distillation and extraction method. The volatiles were analyzed using gas chromatography-mass spectrometry and gas chromatography/sniffing, and the results of the two beef samples were compared. The authors suggested that lactones, i.e., $\gamma$-nonalactone, $\gamma$-decalactone, $\delta$-decalactone, and $\delta$-undecalactone, contributed to the sweet sensation of JBK beef aroma. Uncooked beef actually contains lactones ranging from $C_{10}$ to $C_{18}$ [33], whereas lactones identified from boiled beef range from $\mathrm{C}_{4}$ to $\mathrm{C}_{12}$ [34]. Thus, it is most likely that lactones identified in cooked beef are generated during the cooking process. Watanabe and Sato (1970) [35] suggested that hexanal, heptanal, octanal and nonanal are the main compounds converted into lactones. Since: 1) neutral lipid contents of JBK beef are relatively high; and 2) heptanal, octanal and nonanal (products of C18:1 (n-9)) are relatively high in volatiles from cooked JBK beef, the hypothesis proposed by Matsuishi et al. (2004) [32], that lactones which have a coconut-and peach-like aroma contribute to the part of sweet sensation of JBK beef aroma is supported herein. In addition, $(E)$-2-decenal, which has a mandarin orange odor, may directly affect JBK beef aroma because its boiling temperature is the lowest $\left(78^{\circ} \mathrm{C}-80^{\circ} \mathrm{C}\right)$ among the aldehyde volatiles generated from C18:1 (n-9).

In 2015, the Ministry of Agriculture, Forestry, and Fisheries of Japan set new cattle breeding objectives designedto improve beef flavor through the alteration of fatty acid composition [36]. To date, most Japanese scientists have focused on the association between C18:1 (n-9) composition in JBK beef and genes that mediate its synthesis, e.g, FASN [2], SCD [3], and SREBP1 [4] in an effort to increase C18:1 (n-9) composition. Yokota et al. (2012) [37] reported that SNPs in FASN and $S C D$ significantly influenced myristic, stearic and C18:1 (n-9) composition, although the SNPs did not affect C18:2 (n-6) composition in JBK beef. Meanwhile, the results of this study suggesta significant association between a SNP in FADS2 and C18:2 (n-6) composition in JBK beef. Westerling and Hedrick (1979) [38] reported that flavor scores of cooked Hereford beef were negatively associated with C18:2 (n-6) composition. Predominant volatiles generated from C18:2 (n-6) in cooked beef are hexanal and 2, 4-decadienal, which produce green and fatty odors, respectively. Since hexanal is the most prominent volatile in cooked beef, decreasing C18:2 (n-6) composition may decrease hexanal production and as a result, reduce undesirable odor during storage and cooking process.

On the other hand, decreasing C18:2 (n-6) composition may lead to an increase in C20:4 (n-6), since C20:4 (n-6) is synthesized from C18:2 (n-6) stores within the body. C20:4 (n-6) can improve food taste by activating the TRPM5 cation channel, which is considered as a component of the sweet, umami and bitter taste pathway of Type II receptor cells [6] [7], although C20:4 (n-6) composition could not be determined in the this study. Reckmeyer et al. (2010) [39] reported that neither C18:1 nor C18:2 (n-6) increased or decreased the intensity of sweet, sour, umami and salty tastes, when nose clips were used as additional precautionary measures against olfaction affecting taste and intensity. Matsuichi et al. [21] reported that it was difficult for sensory panelists to 
identify species of cooked meat (beef, pork, lamb, chicken and duck), when their noses were pinched. These reports suggest that sensory evaluation of odor and taste in cooked beef should be distinguished and differentiated.

QTL and markers associated with C18:2 (n-6) composition in beef have not been registered in the JBrowse Genome Browser (2009) [40] and Cattle QTLdb Browser (2005) [41]. Matsumoto et al. (2012) [42] reported that FADS2 g. $-823 \mathrm{G}>\mathrm{A}$ (rs382438496 in Table 2) had a significant effect on percentage of myristic acid (C14:0) in perinephric fat, and percentages of palmitic acid (C16:0), monounsaturated fatty acid and saturated fatty acid in intramuscular fat of the diaphragm in JBK cattle, but they did not find any association between rs382438496 and C18:2 (n-6) composition. SNP lists of multiple commercial bovine SNP chips were screened and findings revealed that rs135659079 in exon 2 and rs110020495 in the 3'-untranslated region were listed in the Axiom ${ }^{\circledR}$ Genome-Wide BOS 1 Bovine Array (Affymetrix, Santa Clara, USA), whereas rs211580559 described in this study and rs382438496 have not been listed in any commercial SNP chip. Our results showed that there was no linkage disequilibrium among rs 211580559 , rs382438496, rs 135659079 and rs110020495. Therefore, even if significant associations between C18:2 (n-6) composition and the other three SNPs (rs382438496, rs 135659079, and rs110020495) were not reported previously, it is an undeniable fact that rs211580559 is associated with $\mathrm{C} 18: 2$ (n-6) composition.

\section{Conclusion}

In conclusion, to our knowledge, this is the first study that evidently demonstrates that a non-synonymous SNP in FADS2 (rs211580559) is associated with C18:2 (n-6) composition in JBK beef. Further research is needed to better understand the relationships among $\mathrm{C} 18: 2$ (n-6) compositions and its metabolic substance including C20:4 $(\mathrm{n}-6)$, and odor and taste perception in JBK beef.

\section{References}

[1] Namikawa, K. (2008) Breeding History of Japanese Beef Cattle. http://www.blackmorewagyu.com/pdf/wagyu/index.html

[2] Abe, T., Saburi, J., Hasebe, H., Nakagawa, T., Mismi, S., Nade, T., Nakajima, H., Shoji, N., Kobayashi, M. and Kobayashi, E. (2009) Novel Mutations of the FASN Gene and Their Effect on Fatty Acid Composition in Japanese Black Beef. Biochemical Genetics, 47, 397-411. http://dx.doi.org/10.1007/s10528-009-9235-5

[3] Taniguchi, M., Utsugi, T., Oyama, K., Mannen, H., Kobayashi, M., Tanabe, Y., Ogino, A. and Tsuji, S. (2004) Genotype of Stearoyl-CoA Desaturase Is Associated with Fatty Acid Composition in Japanese Black Cattle. Mammalian Genome, 15, 142-148. http://dx.doi.org/10.1007/s00335-003-2286-8

[4] Hoashi, S., Ashida, N., Ohsaki, H., Utsugi, T., Sasazaki, S., Taniguchi, M., Oyama, K., Mukai, F. and Mannen, H. (2007) Genotype of Bovine Sterol Regulatory Element Binding Protein-1 (SREBP-1) Is Associated with Fatty Acid Composition in Japanese Black Cattle. Mammalian Genome, 18, 880-886. http://dx.doi.org/10.1007/s00335-007-9072-y

[5] Matsuishi, M. (2007) Palatability of Meat-Rich Flavor Caused by Aroma. Foods \& Food Ingredients Journal of Japan, 212, 929-940. (In Japanese)

[6] Kiyohara, R., Yamaguchi, S., Rikimaru, K. and Takahashi, H. (2011) Supplemental Arachidonic Acid-Enriched Oil Improves the Taste of Thigh Meat of Hinai-Jidori Chickens. Poultry Science, 90, 1817-1822. http://dx.doi.org/10.3382/ps.2010-01323

[7] Takahashi, H., Rikimaru, K., Kiyohara, R. and Yamaguchi, S. (2012) Effect of Arachidonic Acid-Enriched Oil Diet Supplementation on the Taste of Broiler Meat. Asian-Australasian Journal of Animal Sciences, 25, 845-851. http://dx.doi.org/10.5713/ajas.2011.11517

[8] Malerba, G., Schaeffer, L., Xumerle, L., Klopp, N., Trabetti, E., Biscuola, M., Cavallari, U., Galavotti, R., Martinelli, N., Guarini, P., Girelli, D., Olivieri, O., Corrocher, R., Heinrich, J., Pignatti, P.F. and Illig, T. (2008) SNPs of the FADS Gene Cluster Are Associated with Polyunsaturated Fatty Acids in a Cohort of Patients with Cardiovascular Disease. Lipids, 43, 289-299. http://dx.doi.org/10.1007/s11745-008-3158-5

[9] Jakobsson, A., Westerberg, R. and Jacobsson, A. (2006) Fatty Acid Elongases in Mammals: Their Regulation and Roles in Metabolism. Progress in Lipid Research, 45, 237-249. http://dx.doi.org/10.1016/j.plipres.2006.01.004

[10] Sambrook, J. and Russell, D.W. (2001) Molecular Cloning: A Laboratory Manual. Cold Spring Harbor Laboratory Press, Cold Spring Harbor.

[11] University of California, Santa Cruz (2004) UCSC Genomes Browser Home. http://genome.ucsc.edu/

[12] European Bioinformatics Institute (2004) Ensembl Genomes Home. http://ensemblgenomes.org/ 
[13] Lewis B.P., Burge C.B. and Bartel, D.P. (2005) Conserved Seed Pairing, Often Flanked by Adenosines, Indicates That Thousands of Human Genes Are MicroRNA Targets. Cell, 120, 15-20. http://dx.doi.org/10.1016/j.cell.2004.12.035

[14] Barrett, J.C., Fry, B., Maller, J. and Daly, M.J. (2005) Haploview: Analysis and Visualization of LD and Haplotype Maps. Bioinformatics, 21, 263-265. http://dx.doi.org/10.1093/bioinformatics/bth457

[15] Folch, J., Lees, M. and Sloane Stanley, G.H. (1957) A Simple Method for the Isolation and Purification of Total Lipids from Animal Tissues. Journal of Biological Chemistry, 226, 497-509.

[16] Pérez-Enciso, M. and Misztal, I. (2004) Qxpak.5: Old Mixed Model Solutions for New Genomics Problems. BMC Bioinformatics, 12, 202. http://dx.doi.org/10.1186/1471-2105-12-202

[17] Falconer, D.S. and Mackay, T.F.C. (1996) Introduction to Quantitative Genetics. 4th Edition, Longman Group, London.

[18] National Cattlemen's Beef Association (2006) The Chemistry of Beef Flavor-Executive Summary. http://www.beefresearch.org/cmdocs/beefresearch/pe_executive_summaries/the_chemistry_of_beef_flavor.pdf

[19] Mottram, D.S. (1998) Flavor Formation in Meat and Meat Products: A Review. Food Chemistry, 62, 415-424. http://dx.doi.org/10.1016/S0308-8146(98)00076-4

[20] Pearson, A.M., Wenham, L.M., Carse, W.A., McLeod, K., Davey, C.L. and Kirton, A.H. (1973) Observations on the Contribution of Fat and Lean to the Aroma of Cooked Beef and Lamb. Journal of Animal Science, 36, 511-515.

[21] Matsuishi, M., Igeta, M., Takeda, S. and Okitani, A. (2004) Sensory Factors Contributing to the Identification of the Animal Species of Meat. Journal of Food Science, 69, S218-S220. http://dx.doi.org/10.1111/j.1365-2621.2004.tb11008.x

[22] Gray, J.I., Goma, E.A. and Buckley, D.J. (1996) Oxidative Quality and Shelf Life of Meats. Meat Science, 43, 111-123. http://dx.doi.org/10.1016/0309-1740(96)00059-9

[23] Pearson, A.M., Love, J.D. and Shorland, F.B. (1977) "Warmed-Over" Flavor in Meat, Poultry, and Fish. Advances in Food Research, 23, 1-74. http://dx.doi.org/10.1016/S0065-2628(08)60326-2

[24] Frankel, E.N., Selke, E., Neff, W.E. and Miyashita, K. (1992) Autoxidation of Polyunsaturated Triacylglycerols. IV. Volatile Decomposition Products from Triacylglycerols Containing Linoleate and Linolenate. Lipids, 27, 442-446. http://dx.doi.org/10.1007/BF02536386

[25] Enser, M., Hallett, K.G., Hewett, B., Fursey, G.A.J., Wood, J.D. and Harrington, G. (1998) Fatty Acid Content and Composition of UK Beef and Lamb Muscle in Relation to Production System and Implications for Human Nutrition. Meat Science, 49, 329-341. http://dx.doi.org/10.1016/S0309-1740(97)00144-7

[26] Larick, D.K., Hedrick, H.B., Bailey, M.E., Williams, J.E., Hancock, D.L., Garner, G.B. and Morrow, R.E. (1987) Flavor Constituents of Beef as Influenced by Forage- and Grain-Feeding. Journal of Food Science, 52, 245-251. http://dx.doi.org/10.1111/j.1365-2621.1987.tb06585.x

[27] Mahungu, S.M., Hansen, S.L. and Artz, W.E. (1994) Quantitation of Volatile Compounds in Heated Triolein by Static Headspace Capillary Gas Chromatography/Infrared Spectroscopy-Mass Spectrometry. Journal of the American Oil Chemists' Society, 71, 453-455. http://dx.doi.org/10.1007/BF02540530

[28] Ministry of Agriculture, Forestry and Fisheries of Japan (2007) Wagyu, Japanese Beef. http://www.maff.go.jp/e/foj/food/wagyu.html

[29] Litwinienko, G. and Kasprzycka-Guttman, T. (2000) Study on the Autoxidation Kinetics of Fat Components by Differential Scanning Calorimetry. 2. Unsaturated Fatty Acids and Their Esters. Industrial \& Engineering Chemistry Research, 39, 13-17. http://dx.doi.org/10.1021/ie990552u

[30] Boylston, T.D., Morgan, S.A., Johnson, K.A., Wright, R.W., Busboom, J.R. and Reeves, J.J. (1996) Volatile Lipid Oxidation Products of Wagyu and Domestic Breeds of Beef. Journal of Agricultural and Food Chemistry, 44, 1091-1095. http://dx.doi.org/10.1021/jf950373x

[31] Boylston, T.D., Morgan, S.A., Johnson, K.A., Busboom, J.R., Wright, R.W. and Reeves, J.J. (1995) Lipid Content and Composition of Wagyu and Domestic Breeds of Beef. Journal of Agricultural and Food Chemistry, 43, 1202-1207. http://dx.doi.org/10.1021/jf00053a015

[32] Matsuishi, M., Kume, J., Itou, Y., Takahashi, M., Arai, M., Nagatomi, H., Watanabe, K., Hayase, F. and Okitani, A. (2004) Aroma Components of Wagyu Beef and Imported Beef. Nihon Chikusan Gakkaiho, 75, 409-415. (In Japanese) http://dx.doi.org/10.2508/chikusan.75.409

[33] Watanabe, K. and Sato, Y. (1968) Aliphatic $\gamma$ - and $\delta$-Lactones in Meat Fats. Agricultural and Biological Chemistry, 32, 1318-1324. http://dx.doi.org/10.1271/bbb1961.32.1318

[34] Migita, K., Takahama, Y., Takahagi, Y., Sugiyama, N., Kikuchi, K., Matsuishi, M. and Okitani, A. (2012) Analysis of Aroma Compounds of Heated Fats from Wagyu Beef and Other Cattle Using Headspace SPME. Nippon Shokuhin Kagaku Kogaku Kaishi, 59, 127-138. (In Japanese) http://dx.doi.org/10.3136/nskkk.59.127 
[35] Watanabe, K. and Sato, Y. (1970) Conversion of Some Saturated Fatty Acids, Aldehydes, and Alcohols into $\gamma$ - and $\delta$-Lactones. Agricultural and Biological Chemistry, 34, 464-472. http://dx.doi.org/10.1271/bbb1961.34.464

[36] Ministry of Agriculture, Forestry and Fisheries of Japan (2015) Aim of Livestock Breeding Improvement and Propagation. (In Japanese) http://www.maff.go.jp/j/chikusan/kikaku/lin/l hosin/pdf/h27 katiku mokuhyo.pdf

[37] Yokota, S., Sugita, H., Ardiyanti, A., Shoji, N., Nakajima, H., Hosono, M., Otomo, Y., Suda, Y., Katoh, K. and Suzuki, K. (2012) Contributions of FASN and SCD Gene Polymorphisms on Fatty Acid Composition in Muscle from Japanese Black Cattle. Animal Genetics, 43, 790-792. http://dx.doi.org/10.1111/j.1365-2052.2012.02331.x

[38] Westerling, D.B. and Hedrick, H.B. (1979) Fatty Acid Composition of Bovine Lipids as Influenced by Diet, Sex and Anatomical Location and Relationship to Sensory Characteristics. Journal of Animal Science, 48, 1343-1348.

[39] Reckmeyer, N.M., Vickers, Z.M. and Csallany, A.S. (2010) Effect of Free Fatty Acids on Sweet, Salty, Sour and Umami Tastes. Journal of Sensory Studies, 25, 751-760. http://dx.doi.org/10.1111/j.1745-459X.2010.00303.x

[40] University of California, Berkeley (2009) JBrowse Genome Browser. http://jbrowse.org/

[41] University of California, Davis (2005) CattleQTLdb (Cattle Quantitative Trait Locus Database) Browser. http://www.animalgenome.org/cgi-bin/QTLdb/BT/index

[42] Matsumoto, H., Nogi, T., Tabuchi, I., Oyama, K., Mannen, H. and Sasazaki, S. (2014) The SNPs in the Promoter Regions of the Bovine FADS2 and FABP4 Genes Are Associated with Beef Quality Traits. Livestock Science, 163, 34-40. http://dx.doi.org/10.1016/j.livsci.2014.02.016 